\title{
SEDUCCIÓN Y CONQUISTA: UNA LECTURA DE GUAMÁN POMA
}

\section{Alejandra Osorio}

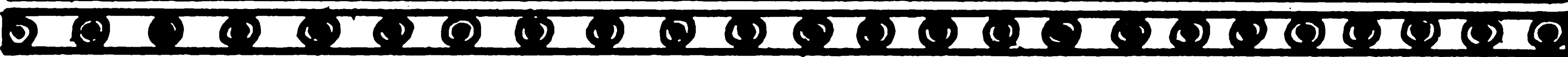

La grandesa que tubo este dicho Mundo Nuebo de las Yndias de tener donzella de treynta y tres años: algunas hasta murir fueron uírgenes donzellas, lo qual se estaua en sus casas $y$ andauan en el campo cin que la mosca le tocase.

¡O que lindo ley, no tan solamente de la tierra cino de Dios! $\mathrm{Ci}$ estaua en la ley de cristiano, quéstas se sacauan para calles y para uírgenes, no lo a tenido tan linda ley enperador ni rreys del mundo. Estas dichas seruían en todo lo que era mandado del Ynga y justicia.

Todo lo malo adulterio $y$ otros pecados mortales trajo concigo los dichos cristianos; con color de la doctrina desuirga a todas las donzellas y aní [sic] paren muchos mestisos en este rreyno. GUAMAN POMA 1980:199/223[226].

LA VIRGINIDAD -y la pérdida de esta- por la mujer andina constituye uno de los temas centrales de la Carta que 


\section{Alejandra Osorio}

Guamán Poma dejó para el rey de España, Felipe III, titulada Nueva Corónica y Buen Gobierno, por el año de 1615. Para Guamán Poma la virginidad encarnada en las acllacuna ${ }^{1}$ fue sinónimo de orden y de grandeza, mientras que la violación de esta virginidad es presentada como el paradigma central de la catástrofe social -"el mundo al revés"- que trajo la conquista para los pueblos andinos. "La utopía andina" de Guamán Poma también resulta estar centrada en esta tesis. La superioridad moral de los Incas se basó en tener una institución parecida a la cristiana que permitió regular "el apetito sexual" de sus súbditos: los aclla huasi, o sea los 'conventos de monjas' de los Incas.

El tema de la mujer y la sexualidad en Guamán Poma, ha sido poco tratado por la historiografía o crítica literaria pertinente. ${ }^{2}$ En este trabajo pretendemos acercarnos al discurso que Guamán Poma maneja acerca de la mujer andina, en términos de "la utopía andina" propuesta por Burga (1988) y Flores Galindo (1987), como también dentro de un análisis de la imagen de la mujer andina como un "otro" (Todorov 1985) ${ }^{3}$ parcialmente culpable de los males coloniales.

'En Quechua o Runa Simi "cuna" es un sufijo pluralizador. Así, acllas o acllacunas viene a ser una hispanización de la forma plural. La práctica lingüistica de reemplazar "cuna" con " $s$ " es muy común hoy en día.

2 Quizá se deba este vacio a lo que Macera (1977) llamó un tabú de tratar temas sexuales en la historiografia peruana. De otra manera no se explica, ya que es realmente una obsesión de Guamán Poma.

"Esta idea del "otro", ha sido explorada en forma elocuente por Rzuetan Todorov (1985). Este, nos proporciona diversas concepciones del "otro". Una de ellas es la del "otro" en relación a nosotros mismos, $y / 0$ como un grupo social especifico al cual "yo" no pertenezco (p.e. otra sociedad). Todorov alega que este grupo puede, también, ser interno a "nuestra" sociedad, en cuyo caso el "otro" sería: las mujeres para los hombres, los ricos para los pobres, los locos para los "normales", etc. (1985:3). Todorov eligió el caso del "otro" exterior y remoto de Cristóbal Colón en la conquista de América. Para este 
La idea del "otro" dentro del discurso de Guamán Poma toma diferentes formas. Guamán Poma fue un hombre andino decididamente cristianizado, que perteneció a las etnias conquistadas por los Incas, experimentando la conquista española como miembro de un grupo, ya derrotado una vez. Ambos factores contribuyen a que Guamán Poma esté fuera de dos grupos que critica severamente en su discurso: los españoles $y$, en especial, las mujeres andinas.

Pensar la Conquista: el Pecado y la Utopia Andina

Para Guamán Poma la llegada de los españoles estuvo plagada de daños y abusos. El interés que movía a los españoles, según él, era: la codicia por el oro y la plata, los productos de los indios y sus vestidos (Guamán Poma 1980:367/395[397]). Los españoles, además de robarles les ultrajaron a sus mujeres:

Cómo después de auer conquistado y de auer rrobado comensaron a quitar las mugeres y donzellas y desuirgar por fuersa. Y no queriendo, le matauan como a perros y castigaua cin temor de Dios ni de la justicia. Ni auía justicia (Guamán Poma 1980:367/295[397]).

Estos maltratos por parte de los españoles no eran simplemente abusos, eran pecados ${ }^{4}$ contra la fe católi-

trabajo he elegido una concepción del "otro" interior y cercano: la visión de Guamán Poma de la mujer andina, antes y después de la conquista española.

\section{- Según Poma:}

[Cuando un joven y una joven tienen relaciones sexuales por su cuenta, es un pecado mortal. Ser fornicador es pecado. Con un pariente es pecado. Violar a una joven es pecado. Relaciones sexuales con un padre saserdote, que es representante de Dios, es pecado mortal.] (Guamán Poma 1980:585/616[630]). 


\section{Alejandra Osorio}

ca de los mismos. El producto de estos pecados era la proliferación de mestizos y la caída de la población andina.

La crisis demográfica que se suscitó, inmediatamente después de la conquista española, contribuyó a que, en la mente de los andinos, "conquista" se constituyera en sinónimo de muerte. Las nuevas demandas de trabajo impuestas por el régimen colonial y la proliferación de las epidemias fueron factores responsables de la alta mortandad de los andinos que se produjo en el siglo XVI (Sánchez-Albornoz 1973). La población aproximada del territorio peruano hacia 1530 fue de 2'738,673 habitantes; hacia 1630 había disminuido a 601,645 habitantes (Cook 1973; citado en Flores Galindo 1987:39). Esta súbita despoblación del territorio preocupó a los mismos españoles, ya que la extracción de las riquezas dependía de la disponibilidad de la mano de obra barata proporcionada por los andinos.

En su Carta, Guamán Poma le señala al Rey Católico de España los peligros que corren sus intereses en las Indias, si no se encuentran soluciones inmediatas a estos problemas:

...se perderá la tierra y quedará solitario y despoblado todo el rreyno y quedará muy pobre el rrey. Por causa del dicho corregidor, padre, comendero y demás españoles que rroban a los yndios sus haziendas $y$ tierras $y$ casas $y$ sementeras $y$ pastos $y$ sus mugeres y hijas, por ací casadas o donzellas, todos paren ya mestisos y cholos. Ay clérigo que tiene uey[n]te hijos y no ay rremedio (Guamán Poma 1980:413-4/446[448]).

Como veremos más adelante, las soluciones que Guamán Poma sugiere al Rey para frenar los abusos y restaurar la población andina, se basan en fundamentos católicos de castidad femenina y de segregación de razas. En la elaboración de su argumento yuxtapone una visión 


\section{SEDUCCION Y CONQUTSTA}

utópica y cristianizada de la sociedad andina bajo los Incas $y$ los reinos preincaicos, con una feroz condenación de la sociedad colonial. Con esto Guamán Poma logra asumir una autoridad moral -como escritor y "principe" andinofrente a la corrupción y explotación colonial (Adorno 1989).

\section{La Conquista como Seducción: de Acllas}

\section{A AMANCEBADAS}

Dos son las imágenes que Guamán Poma nos proporciona de la mujer andina: la de antes y la de después de la Conquista. Una está relacionada con la idea que Guamán Poma tuvo de la mujer andina y su comportamiento correcto bajo el Inca y la otra es de la mujer andina transformada y contaminada por la conquista española. La primera imagen está asociada con la pureza y el orden y la última con la corrupción y el desorden, consecuencia de la colonización española. Sin embargo, estos conceptos tienen un sentido más amplio dentro del discurso de Guamán Poma, extendiéndose la analogía a su visión moralista y católica de la conquista: los Incas -hombres y mujeres- fueron moralmente superiores a los españoles. Pero, y como consecuencia de la conquista española, sólo los hombres andinos retienen esta virtud. ${ }^{5}$

\section{La Mujer Andina Bajo los Incas: Las Coyas}

En la primera parte de su carta al rey, "Nueva Corónica", Guamán Poma dedica doce capítulos a la descripción de las doce Coyas o reinas que gobernaron las diferentes

${ }^{5}$ Guamản Poma toma parte en el pensamiento católico y machista de la época que identifica a las mujeres como seres débiles susceptibles a la degeneración moral. 


\section{Alejandra Osorio}

regiones del Tawantinsuyo 6 (ver Guamán Poma 1980:99/ 121[121]-121/142[143]). Guamán Poma describe las idiosincracias ${ }^{7}$ de cada una de ellas y las influencias que ejercieron en los pueblos que gobernaron. Los retratos de las Coyas son benévolos y no contienen adjetivos condenatorios -como los que utilizará más adelante para referirse a las mujeres andinas comunes colonizadas por los españoles. Guamán Poma se abstiene de emitir una opinión moralista de las vidas de las Coyas. Un caso muy ilustrativo es el de Mama Huaco.

La primera descripción de Mama Huaco que nos ofrece Guamán Poma, se encuentra en la historia del primer Inca Tocai Cápac. En ella Guamán Poma la retrata de manera no muy positiva: era una embustera que se acostaba con todos los hombres de su pueblo.

...dicha muger dizen que fue gran fingedora, ydúlatra, hichesera, el qual hablaua con los demonio' del ynfiemo y hazía serimonias y hecheserías. $Y$ aci hazía hablar piedras $y$ peñas y palos $y$ zerros y lagunas porque le rrespondía los demonios. Y ací esta dicha señora fue primer enbentadora las dichas uacas ydolos y hecheserías, encantamientos, y con ello les engañó a los dichos yndios. Primero fue engañado del Cuzco y trayya engañado y sugeto, como los yndios lo uiesen como cosa de milag[r]o que una muger hablase con piedras $y$ peñas $y$

- El imperio Inca denominado Tawantinsuyu -'la unión de cuatro que encajan juntos'- estuvo dividido en cuatro regiones, o direcciones procedentes desde el Cusco. Hacia el sur se encontraba Collasuyu; hacia el este el Antisuyu y hacia el oeste el Condesuyu; hacia el norte se encontraba Chinchaysuyu que se extendía desde el Cusco proyectándose hacia lo que hoy en día constituye el sur de Colombia.

${ }^{7}$ Lo cual ha sido señalado como una característica muy particular de la obra de Guaman Poma, comparado con los escritos de la época (conversación personal con Frank Salomon, Lima 1990). 


\section{SEDUCCION Y CONQUISTA}

serros. Y ací fue obedecida y seruida esta dicha señora Mama Uaco, y aci le llamaron Coya y rreyna del Cuzco. Dizen que se echaua con los hombres que ella quería de todo el pueblo, como este engaño andaua muchos años, según cuentan los dichos muy biejos yndios.

Questa dicha Mama fue llamado primero "mama" quando entró a ser señora: Se llamó Mama Uaco despues que se cazó con su hijo y entró a ser señora y rreyna... Dizen que la madre fue mundana y encantadora, la primera que comensó a seruir y tratar a los demonios (Guamán Poma 1980:634/81[81],82[82]).

Sin embargo, el retrato que Guamán Poma nos ofrece de Mama Huaco más adelante cuando describe a las doce collas, aunque contiene el trasfondo de lo que nos dice en la primera historia del Inca, ahora el lenguaje es substancialmente diferente. Guamán Poma omite los adjetivos condenatorios como "fingedora", a la vez que suavisa "se echaua con los hombres" convirtiéndolo en "fue muy amiga de los caballeros y demás gentes":

Dizen que fue gran hechizera, según cuentan su uida $y$ historia, que hablaua con los demonios. Esta dicha señora hacía hablar a las piedras y peñas, ydulos guacas. Desta señora comensaron a salir rreys Yngas. $Y$ dizen que ella no le fue conocida su padre ni de su hijo Manco Cápac Ynga, cino que dixo que era hija del sol y de la luna $y$ se casó con su hijo primero, Mango Cápac Ynga...

Y esta señora dejó la ley del demonio muy entablado a todos sus hijos $y$ nietos $y$ desendientes. Pero fue muy amiga de los caualleros y demás gentes. Gouernaua más que su marido Mango Cápac Ynga; toda la ciudad del Cuzcoco le obedecieron y rrespe- 


\section{Alejandra Osorio}

taron en toda su uida, porque hazía milagros de los demonios nunca uista de hombres. Hablaua como ci fuera persona con las peñas y piedras. Con ello acabó su uida esta señora Mama Uaco.

Pero fue muy hermocícima muger $y$ de mucho sauer y hazía mucho bien a los pobres en la ciudad del Cusco y de todo su rreyno. Y ací creció más bien su gobierno de su marido desta señora coya porque reynaua el Cusco y su juridición (Guamán Poma 1980:99/121[121]).

Esta enmienda del texto original fue ejecutada por Guamán Poma después del viaje a Lima que le "abrió los ojos" a los abusos y el desprecio que profesaban los españoles hacia lo andino. ${ }^{8}$ El propósito principal de

${ }^{8}$ En la tercera parte de su Carta al Rey, Guamán Poma hace una enmienda al texto (Adorno 1989: 64-82). La tesis central de esta enmienda es la destrucción que sufre el pueblo andino como consecuencia de la proliferación de los mestizos y la reducida reproducción biológica de los indios. El cambio se produjo, presumiblemente después de su viaje a Lima ca. 1612-14, durante el cual se percató de las atrocidades cometidas por los españoles en contra de los pueblos andinos, así como del odio que existía hacia todo lo andino -que hasta ese entonces le era (presuntamente) desconocido. La especial preocupación que Guamán Poma tenía con la Iglesia como institución social y guía espiritual, persistió, a pesar de las atrocidades cometidas en su afán evangelizador (Adorno 1989:76). Sin embargo, desde ese momento la Iglesia para Guamán Poma, ya no es solamente un potencial salvador, sino que la concibe también, como un poder destructor. Dentro de este contexto es que Guamán Poma interpretó las campañas de extirpación de 1614 llevadas a cabo por Francisco de Avila que lo llevó a enfatizar la imperante necesidad de encontrar soluciones a la situación crítica de la población andina (Adorno 1989:77-8).

La transformación que sufrió Poma después de su viaje a Lima, fue similar a la sufrida por Garcilaso de la Vega en España, donde decidió que la única pretensión de nobleza válida en el mundo virreinal, era la identificación con los Incas. Poma de igual manera hace de su descendencia incaica -por el lado materno- la base de su legitimidad (ver Poma 1980:49/60[60],61[61] y Adorno 1989:7882). 
la enmienda al retrato de Mama Huaco fue el de incluir y resaltar su descendencia incaica por el lado materno. Lo mismo que lleva a Guamán Poma, más adelante, a añadir el honorífico "Curi Ocllo" al nombre de "doña Juana, coya", su madre (Adorno 1989:80).

Los retratos que nos presenta Guamán Poma de las Coyas, revelan mujeres con personalidades definidas. Son las únicas que las tienen. En la obra de Guamán Poma, la mujer andina después de la Conquista no merece mayor atención personal. Se me ha señalado 9 que esto podría obedecer a una tendencia en Guamán Poma de exaltar y glorificar la nobleza Inca, en términos de la utopía aristocrática andina señalada por Burga (1987: 235-400), con la que él aspiraba a ser identificado -como señor $y$ príncipe- $y$ así legitimizarse en los ojos del rey de España (Burga 1987 y Adorno 1989). Dentro de este contexto se explicaría el por qué Guamán Poma describe en detalle a los nobles Incas y no a la plebe.

Dos aspectos esenciales atribuidos por Guamán Poma a la sociedad incaica fueron la pureza y el orden. A pesar que alega constantemente que no existió el incesto en el incanato, en el relato de Mama Huaco nos dice que se casó con su hijo primogénito, Manco Cápac. Desde una perspectiva andina resulta lógico que Guamán Poma cometiera aparentes "contradicciones" en su afán de describir a los andinos libres de pecados: los sistemas de parentesco andinos no eran necesariamente, análogos a los esquemas europeos. En la mitología andina existen muchos casos de mujeres que tuvieron numerosos amantes, como el caso de Chaupiñamca descrito en el manuscrito de Huarochirí (Taylor 1887:197), al igual que el incesto era parte integra y hasta necesaria en los mitos de origen. Esto puede explicar en parte por qué Guamán Poma no juzga moralmente el comportamiento de Mama

- Le agradezco a Mark Thurner el haber señalado esta posibilidad. 


\section{Alejandra Osorio}

Huaco, siendo su figura hasta cierto punto, objeto de un "culto de personalidad".

La pureza y el orden reinante en el estado incaico, para Guamán Poma se traducía en la virginidad de sus mujeres y la castidad observada por todos los habitantes por igual. En su relato de los purun runas, o pobladores de la tercera edad, según Guamán Poma entre

...sus mugeres no se halló adúltera ni auída puta ni puto porque tenían una rrecla que mandaua que las dichas mugeres no le auian de dalle de comer cosa de sustancia ni ueuía chicha. Tenía esta ley y ancí no se hacía garañona ni adúltera en este rreyno las yndias mugeres.

De cómo se casauan uírgenes y donzellas y lo tenían por onrra de ellos y la uirginidad te [sic] de edad de treynta años. ... (Guamán Poma 1980:48/ 59[59]).

En su afán de convencer al lector de la "pureza y moralidad" de los Incas, Guamán Poma niega el uso de elementos esenciales, tales como la chicha, en los rituales andinos (ver Cavero 1986). Con el mismo fin, alega que la castidad y virginidad de las mujeres incas implicaba que si ellas hubieran conocido el cristianismo, los incas hubieran tenido muchas monjas, lo cual se traduce en "buenos cristianos":

De cómo no abía monjas antiguamente por los trauajos y guerras que tenían entre ellos. $Y$ demás de eso no se acordaron tenella; harta monja auía ci las mugeres eran de treynta y quarenta años donzellas. $¡ \mathrm{O}$, que buena monja ci se conuertiesen en el seruicio de Dios entonses! (Guamán Poma 1980:53/66[66]). 


\section{SEDUCCION Y CONQUISTA}

Su discurso aquí es siempre apologético: los Incas no tuvieron monjas porque no se acordaron de tenerlas, tenian otras cosas de qué preocuparse. Guamán Poma alega ignorancia de la "fe" por parte de los Incas como una manera de absolver los "pecados" que la Iglesia colonial intentaba extirpar.

Para lograr convencer al lector de las buenas intenciones de los andinos, Guamán Poma contrasta el comportamiento de los Incas con la degeneración de los españoles y en especial de los curas cristianos. Es así que los indios que habitaron los Andes durante la cuarta edad fueron capaces de llevar vidas libres de "inmoralidades" porque:

... Comían y beuían y se holgauan cin tentación de los demonios, ni se matauan ni se emborrachauan como en este tienpo de español cristiano. Son todos borrachos y matadores, canbalacheros y no ay justicia (Guamán Poma 1980:54/67[67]).

En constraste, los "españoles cristianos" son borrachos y corruptos. Su relato continúa haciendo hincapié en que las mujeres "se cazauan donzellas de treynta años $y$ de cuarey[n]ta o cinquenta y algunas que no se casauan murieron donzellas", lo cual ya no era posible alega Guamán Poma, porque "agora primero los sazerdotes lo desuirga con color de la doctrina". Poma insiste en la imperancia del orden y la moral como fuente de la justicia incaica:

De cómo no se consentían pecados que ubiesen adulterio ni con ermanas y tías y comadres y sobrinas y parientas sercanas. Destas dichas ci pecauan con las dichas, tenían pena de muerte y grandes castigos. Y auía mucha justicia por el rrey y capitanes y de señores justicias que en el tiempo auía (Guamán Poma 1980:54/67[67]). 


\section{LAS ACLAS Y LOS ACCLLA HUASI}

Como señalamos en el comienzo, la máxima expresión de superioridad moral (cristiana) que Guamán Poma le atribuyó a los Incas fue la institución de las acllas o vírgenes escogidas. A pesar de que las acllas fueron un contingente de mano de obra (ver Rostworowski 1988), Guamán Poma se preocupa de resaltar la virginidad y castidad que practicaron. Las acllas habitaban en los denominados aclla huasi (casa de las escogidas). Tenían también su acllap chacran o sementera de las escogidas, a la vez que poseían sementeras para "seruir los tanbos rreales [mesón en la carretera real] y seruir file]stas" (Guamán Poma 1980:274/300[302]). Los aclla huasi fueron asociados por los españoles con los conventos cristianos. La concepción es errónea ya que la función que tuvieton fue muy diferente del de los conventos cristianos (Rostworowski 1988:11). Los aclla huasi tuvieron tres fines fundamentales. Sirvieron de obrajes destinados a la producción de textiles para el estado Inca (Murra 1975:170), se preocuparon de la producción masiva de bebidas ceremoniales, a la vez que fueron depósitos de mujeres para ser obsequiadas por el Inca, cuando la ocasión política así lo requería (Rostworowski 1988:11).

Las acllas eran las vírgenes de los Incas. Estas se dedicaban a servirlos, tejian ropa, preparaban la chicha y los alimentos y "no pecaban" (Guamán Poma 1980:272/ 298[301]-74). Guamán Poma nos da una idea muy detallada de los diversos tipos de acllas que tuvieron los Incas, como de sus funciones. Las escogidas principales eran denominadas guayrur aglla, eran de veinte años y servian al sol, a la luna, y a las estrellas Chasca Cuyllor [Venus], Chuqui Ylla [¿Marte?]. Estas vírgenes no tenian ningún contacto con los hombres hasta morir. Las súmac aclla o 'escogida hermosa', tampoco trataban con hombres, eran de edad de treinta años, morian vírgenes y servian al ídolo de los Incas Huana Cauri. Guamán Poma menciona las acllas de los idolos menores, haciendo hin- 


\section{SEDUCCION Y CONQUISTA}

capié en la virginidad que conservaban todas hasta la muerte. ${ }^{10}$ Guamán Poma también señala la existencia de vírgenes comunes que se encontraban por todo el reyno $y$ se denominaban aclla panpa ciruec. De este grupo provenian las vírgenes que servian a la comunidad en los sapsis - tierras comunales, las sementeras y la confección de la ropa (Guamán Poma 1980:272/299[309],274/300[302]).

Además de desempeñar las funciones descritas, algunas acllas también proporcionaban diversión para el Inca y sus súbditos. Estas eran cantoras y músicas, actuaban en las diversas fiestas, pascuas, casamientos, uarachicos, rutochicos [ceremonias del ciclo vital] y fiestas del año y meses. Eran niñas de doce años y eran seleccionadas de acuerdo a su buena voz. Estas niñas aprendian a tejer e hilar como el resto de las vírgenes. Por último, Guamán Poma menciona las mamaconas o señoras, a las cuales Guamán. Poma identifica como vírgenes comunes. Estas eran de edad de entre cincuenta y cien años, y se ocupaban de tejer ropa, cuidar las chacras y sementeras.

Luego de una larga descripción de las acllas -con un marcado, casi exagerado énfasis en su perpetua virginidad-, Guamán Poma revela un dato que no encaja con la imagen inmaculada y pura hasta ahora proporcionada de los Incas:

Otra cas[a] de acllaconas del mismo Ynga. Que alguna déstas eran uírgenes, algunas estauan corronpidas y amanzebas del mismo Ynga. Eran hijas de prencipales y éstas se ocupauan sólo en hazer

10 Estas eran las: uayror aclla, sumac ["la escogida del wayruru que es hermosa"l, de edad de veinte y cinco años, las sumac acllap catiquin ["la que sigue a la sumac aqlla"] de edad de treynta y cinco años; las acclla chaupi catiquin sumac aclla ["sumaq aqlla que sigue a la aqlla de status mediano"] de edad de quarenta años; y las pampa acllaconas ["escogidas campesinas"] de edad de cincuenta años. Estas últimas "nunca pecauan y eran hijas de los auquiconas príncipes yngas" (Guamán Poma 1980:272/299[301], 274/300[302]). 


\section{Alejandra Osorio}

rropa para el Ynga mejoor [sic] que tafetán y seda. Y hacía linda chica que de tan bueno maduraua un mes llamado yamor toctoy... asua [chicha] y lindas comidas para el Ynga.

Sin embargo, Guamán Poma inmediatamente lo justifica añadiendo que

Éstas... jamás pecauan con otra persona ni aunque fuese muger de pobre yndio, no auia de pecar con otra persona en toda su uida. $Y$ después de muerto el dicho su marido nunca fue adúltera. Tenía esta ley y buena y santa cristiana. Ci conociesen a Dios que la crió y rredimió, fueran muchas sanctas en este rreyno (Guamán Poma 1980: 275$4300[302] / 301[303])$.

Con lo que no queda claro si Guamán Poma se refiere especificamente a las mancebas del Inca o a las mujeres en general. Lo importante es que logra, de manera muy sutil, justificar el comportamiento que tanto critica, más tarde, cuando se refiere a las mujeres andinas, sus coetáneas, y los españoles. Guamán Poma menciona la ley de los Incas en contra del adulterio, para asociarla con la de los cristianos, y mencionar, una vez más, que los Incas tuvieron muchas santas sin saberlo.

Guamán Poma describe extensamente los castigos que sufrieron los adúlteros en manos de los Incas. E castigo a las adulteras constituye el tercero descrito por Guamán Poma después del zancay o cárcel para los traidores y delincuentes mayores, y la pinas o cárcel destinada a los principales $e$ indios comunes. El cuarto castigo se refiere al que sufrian las vírgenes que violaban su castidad.

Preguntaua ci se consentian los dos y para auello de castigar igualmente fue sentenciado a muerte, tirándole con piedras en el citio que le llaman 


\section{SEDUCCION Y CONQUISTA}

uinpillay len que daban trato de cuerda por un dia]. Y ci le fuerza el hombre a la muger sentencia al hombre a la muerte; a la muger le sentencia ducientos asotes con soga de toclla [lazo] y destierro al depócito de las monjas acllaconas [las escogidas] para que cirua toda su ! uida en aquella casa. Ya no haze uida con su marido porque fue afrentada uachoc, adúltera.

Y ci lo forsó la muger al hombre, le sentencia a la muger a muerte $y$ al hombre a los asotes y destierro a la montaña a los yndios Chunchos para nunca más pareser. $Y$ se se concienten los dos, mueren juntamente $y$ no le an de enterrar que alli le an de comelle los buytris y soras $y$ los gulesos a de estar por los suelos tendidos (Guamán Poma 1980:281/301[309]).

Las acllas entonces no eran siempre vírgenes. ${ }^{11}$ Según este relato los aclla huasi servian tambien de "cárceles" para las infractoras de la ley moral. Guamán Poma hace hincapié en la aplicación de la mano dura, para garantizar la obediencia de los súbditos por parte de los Incas:

Questa justicia y ley tenía en todo el rreyno puesta y los castigaua los corregidores tocricoc y los juecés michoc y jues de comiciones, Quiles Cachi cimi apac. $Y$ anci andaua la tierra muy justa con temoridad de justicia y castigos y buenos egenplos. Con esto parese que era ubidente a la justicia y al Ynga y no auía matadores pil pleyto ni mentira ni peticiones ni proculadrones ni protector ni cura-

"Rostworowski (1988:11) señala que sólo las consagradas al Sol, o Yurac Aclla, permanecian vírgenes y recluidas en los Aclla Huasi. Las demás podian entrar y salir durante el dia. 
dor enteresado ni ladrón, cino todo uerdad y buena justicia y ley (Guamán Poma 1980:281/307[309]). mente severo:

El cuarto castigo aplicado a las vírgenes era igual-

Y anci los dichos forzadores de las mugeres donzellas o forzadores de las mugeres a los donzeles $y$ anci en aquel tiempo se castigaua ci se consentieron los dos, el hombre y la muger. Sentencian a muerte, colgado bibo de los cauellos de una peña llamado arauay [horca] o de Antaca Caca o de Yauar Caca. Alli penan hasta murir (...)

$Y$ mueren colgado.

$\mathrm{Ci}$ le forsó el hombre, muere solo. Y se le forsó la muger, muere la muger solo. El acometedor y el que se dexó acometerse lleua castigo, asotes con chocclo copa, un asote de cabuya, en la punta hecho pelota, de dentro tiene piedra que le muele las entrañas. Con ella le da cinguenta asotes y le saca media muerta al yndio o a la yndia. Cúranle y le sana de ello. Y ésta nunca más se a de casar ni a de ser manseba en su uida, porque le matará por la ley que tienen y porque en su uida ya fue adúltera de la uirginidad, puta pública cin onrra y le desonrró a toda su casta, muera (Guamán Poma 1980:283/309[311]).

Para Guamán Poma la aplicación de castigos severos a los súbditos del Inca -especialmente a las mujeres que violaban los códigos morales- garantizaban la superioridad moral de sus gentes. La repetida mención, que hace Guamán Poma a ello, parece haber tenido el propósito de señalarle al Rey la imperante necesidad de una acción similar de su parte, para con sus súbditos, para terminar con la corrupción de la sociedad colonial que Guamán Poma percibía y describía en su Carta. 
SEDUCCOON Y CONQUISTA

LA MUJER ANDINA BAJO El DOMINIO DE LOS ESPAÑOLES

En el pasado precolombino que Guamán Poma añoraba -el imaginado de los Incas - las mujeres habian sido vírgenes de por vida o por lo menos hasta que se casaban con los hombres designados por el Inca. Todo eso terminó, bruscamente, con la llegada de los españoles. Para Guamán Poma la pérdida del orden, de la inocencia, de la pureza y por último del control, se manifestaron en la pérdida de la castidad de las mujeres andinas. ${ }^{12}$ Guamán Poma responsabilizó a los españoles, curas y oficiales de la corona de corromper a las mujeres andinas, pero también las acusó a ellas de ser sus cómplices en la ruina del Nuevo Reino.

\section{Las "Amansebadas" y las "Putas"}

Algunas (yndias) como an cido coseneras del padre o de comendero o del corregidor o de algún espanol que aya cido criada, amanzeba o tener hijo en él o que aya formicado el dicho español o mestiso o negro, mulato, estas dichas yndias salen enbusteras, bachelleras, ladronas, muy grandes putas, tanberas peresosas, amigas de comer, rregalos y ni cirue a Dios ni a su Magestad no obedece a sus justicias ni a sus caciques prencipales ni a sus padres y madres ni a sus maridos; ellos,

12 Esta pérdida del "verdadero orden y sentido" de las cosas está manifestada muy claramente en uno de los argumentos que utiliza Guamán Poma en su Carta: la restitución de los privilegios a los señores naturales del Perú (Adomo 1989:33-36). Guamán Poma se identificó con los señores naturales, destituidos de sus derechos por los españoles (Burga 1987:234-35). Poma reclamó la restitución de estos derechos, alegando que los usurpadores -0 sea los españoles- no los merecian por ser moralmente inferiores a él. A la vez, que Guamán Poma alegó legitimidad por ser hijo y nieto de Inca (Adomo 1989:79). 


\section{Alejandra Osorio}

ellas tienen este uicio (Guamán Poma 1980:800/ 855[869]).

Para Guamán Poma las mujeres andinas que se relacionan con los conquistadores pierden sus virtudes, convirtiéndose en el paradigma de la corrupción y la decadencia de la sociedad andina conquistada. Al referirse a la plebe andina, femenina, Guamán Poma cambia su lenguaje drásticamente. Las mujeres andinas son tratadas como un todo absoluto, donde las excepciones no existen. "Todas" son: embusteras, golosas, ladronas, desobedientes, y en especial, grandes putas.

El contacto con los españoles para Guamán Poma significó la degeneración de las mujeres andinas. Para Guamán Poma el hecho que los españoles se rehusaran a casarse y vivir "honradamente" con ellas es lamentable. Peor aún, sin embargo, es el hecho que las mujeres andinas prefieran vivir como concubinas de los españoles $-\mathrm{y}$ en ocasiones de negros y mulatos- que casarse con un indio común. Estas "indias" para Guamán Poma son deplorables y peores que "negras" carentes de toda honra. La razón para este comportamiento es simple: el cura o el español las "fornica". Por lo que, una vez que ellas entran en la casa del cura o del español, alega Guamán Poma, abandonan a sus hijos y sus comunidades sin importarles más que su apetito sexual (Guamán Poma 1980:800/855[869]).

El grado de corrupción en el reino es tal, que las mujeres andan en "público pecando y adúlteras", sin honra con negros, mulatos y españoles. Guamán Poma se lamenta que:

... Ya no ay uírgenes como en tiempo de los Yngas, cómo las justicias mayores y padres de las conficiones y de la dotrina, comenderos y todos sus hijos $y$ ermanos y españoles y sus negros están amansebados con las yndias. $\mathrm{Y}$ ancí salen muy muchos mesticillos, mesticillas, cholos y 


\section{SEDUCCION Y CONQUISTA}

cholas. Mala casta aprenden de ellos las dichas yndias. $Y$ ancí no ay rremedio en este rreyno ... Antes rrecrese a más daño por ser la tierra perdida cin justicia. Aunque era bárbaro el Ynga, tenía muy gran justicia y castigo, exenplo. $Y$ aci jamás abía borracha ni golosa. $\mathrm{Y}$ ací no ubo adúltera ni luxuriosa muger, y a ésta luego le mataua en este rreyno (Guamán Poma 1980:807/861[875]).

A medida que progresa la Carta el discurso de Guamán Poma contra la mujer andina $-y$ de los españolesse torna cada vez más extremo y radical:

... Pero a ojos y a uista que lo confieso como lo e bisto, estando borracho ydulatran y formican a sus ermanas y a sus madres, las mugeres casadas. $Y$ las mugeres, estando borrachos, andan salidas; yllas propias buscan a los hombres, no mira ci es [s]u padre ni ermano (Guamán Poma 1980:809/ 863[877]).

La corrupción de las "indias" comienza a muy temprana edad, en las doctrinas, donde los curas, con el pretexto de enseñarles la " $\mathrm{fe}$ " se aprovechan para abusarlas sexualmente. Con la pérdida de la virginidad las niñas se convierten en "putas" sin esperanzas de salvación. Esta pérdida de la virginidad es la causa de la "luxuria" imperante -la cual, añade Guamán Poma- no existió durante los Incas (Guamán Poma 1980:824/878[892]). Estas mujeres se rehusan a casarse porque, "son comunes putas y..." las que se casan no corren una suerte mejor porque "después de casadas son putas, adúlteras y uellacas. Estas se apartan y alcaguietea a otras entre ellas" (Guamán Poma 1980:824/878[892]).

A la vez que las mujeres andinas se convierten en "putas", adquieren también otras características reprochables para Guamán Poma: son peores que los hombres, 


\section{Alejandra Osorio}

tienen apetitos sexuales insaciables (una idea muy cristiana de la sexualidad femenina, por lo demás), con lo cual Guamán Poma logra hacerlas responsables de muchos de (sino de todos) los males sociales que afligen a la sociedad colonial. Es asi que:

... estas putas son causas y dan ocación a que se maten unos con otros por ellas.

... le causa la luxuria mucho más a las mugeres porque son más borrachas que los hombres. Questando ellas borrachas, ellas propias buscan a los hombres y no se harta con un solo. Quantos borrachos ay, le furnica $y$ se huelga de ello. $Y$ ancí le auía quitado a las yndias que no ueuiese ni fuese borracha. Le dio esta ley el Ynga a la muger. $Y$ anci buscan y pecan.

El tersero es que conciente el padre y la madre $y$ con los sacerdotes de las doctrinas y españoles $y$ de que ellas se hazen putas. Y como le aprimia a la dotrina, alli se desuirga el padre, luego sus muchachos dan en ellas $y$ luego sus fiscales $y$ sacristanes, cantores.

Destas enseñansa se entran a los tanbos a buscar españoles y pecan con ellas. $Y$ como uen esto todos los mosos dan en ellas $y$ no ay casarse en el pueblo y se haze comunidad ellas. $Y$ no le castiga los dichos alcaldes ni los caciques principales por miedo al padre. $Y$ lo defiende $y$ se huelga de ello (Guamán Poma 1980:824/866[880]).

Las mujeres tampoco deben ser dignas de confianza:

Que a las yndias deste rreyno no se puede rrecibir por testigo en justicia de crimenal ni de cibil ni de pleytos porque son enbusteras y rreboltosas, enemigo mortal de los hombres y falso testimonieras y lloronas y pobres mugeres: Sollo para dalle limosna a ellas es bueno. 
$Y$ no se puede dar ningún tormento ni cárzel ninguna, cino por cársel se le de a una casa de muger prencipal depocitada dalle su preción. $Y$ se fuere culpada de derecho de justicia, le sea sentenciado a secreta y no le lleue pena por la ley $y$ justicia que Dios le dio como a muger $y$ de sus trauajos a Eua, primera madre (Guamán Poma 1980:801/855 [869]).

Guamán Poma llega al extremo de percibir a "todas" las mujeres de ciertos lugares como "putas". Es asi que los pueblos andinos de "Lurin Uanca y Jauja" (sierra central del Perú), son descritos como "medio de prouincia de yndias hechas putas" (Guamán Poma 1980:1019/1115[1125]). Guamán Poma también relata cómo en el pueblo de San Cristóbal vio muchas indias "amansebadas" y de cómo se mandaba a tres indias hermosas a Huancavelica "adonde le fornique españoles y haga casta de mestizos y sea más uellaca entre español y puta".

Este último dato es interesante, ya que Guamán Poma acusa a los hombres andinos ( $y$ en algunos casos a los padres y las madres) de utilizar o "arrendar" a sus hermanas y mujeres como mancebas a los tamberos, mineros, curas y otros oficiales coloniales:

Y ancí no ay donzellas y les alcaguetean a los españoles y concienten a que tengan los saserdotes $y$ curas de las doctrinas en las cocinas $y$ que entren a sus casas $y$ a los harrieros, mulatos $y$ negros, yanaconas del tanbo y mesón y los lleua a las minas y plasa a bellaquear con los mineros y mayordomos y los dexan salir de sus pueblos. Desde niña le enseñan a sus hijas $y$ ermanas $y$ cuñadas, sobrinas de lo qual meresen castigo las dichas madres y sus padres por ser serbicio de Dios nuestro señor (Guamán Poma 1980:812/ 866[880]). 


\section{Alejandra Osorio}

Según el relato de Guamán Poma, las mancebas, parecen haber ocupado el lugar de las prostitutas convencionales, hasta cierto punto. Esto podría explicar el hecho que estudios (aunque superficiales) sobre prostitución en el Perú colonial, revelan un número muy bajo de mujeres andinas en esta ocupación (Burkett 1978), aunque Guamán Poma se empeñe en calificarlas como tal.

A medida que el discurso de Guamán Poma en contra de la mujer andina se radicaliza, su añoranza por los tiempos pasados del Inca, transforma ese espacio en una sociedad idílica cada vez más pura y perfecta:

Que en tienpo de los Yngas y ací no auía borrachería, aunque ueuían y hacian fiestas y más estaua uedado de que las mugeres que no se enborrachasen, grandes castigos en ellas (1980:809// 863[877]).

Que los dichos yndios destos rreynos an uzado lo que no uzauan los cristianos, ni en tienpo de los Yngas no hazía tal enseñansa. Que sus padres y madres conciente salir a las donzellas con los mosos todas las noches, yr por leña y por estiércoles, sólo a fin de auellaquear $y$ hazerse putas y malas (Guamán Poma 1980:812/866[880]).

Y en su afán por probar la pureza de los andinos Guamán Poma niega, una y otra vez, ciertas prácticas andinas, como la sexualidad premarital, el consumo de la chicha y los alucinógenos, ampliamente difundidas en el mundo andino hasta hoy en día (ver Millones y Pratt 1989; Cavero 1986). En términos generales en la cultura quechua existían y existen dos aspectos del cortejo tradicional que Guamán Poma niega constantemente en su discurso, aunque a veces se le escapa. En primer lugar, el tupanakuy que ha sido traducido como "encuentro y flirteo" (Millones y Pratt 1989:33). Estos encuentros se llevan a cabo en las afueras de las comunidades, generalmente en los pastizales 


\section{SEDUCCON Y CONQUISTA}

altos de la puna donde las mujeres solteras andan solas pastoreando. Lejos de la tutela de los padres, los jóvenes tienen relaciones sexuales que forman parte del ritual de enamoramiento. La segunda etapa, según estos autores, es la denominada wallunakuy o kuyanakuy, que significa "verdaderos amantes" o "estar seriamente en amores". Esta etapa se desarrolla de igual manera en la puna, alejados de los padres y autoridades quienes eventualmente deberán aprobar la relación (Millones y Pratt 1989:34). La ceremonia del matrimonio religioso no se lleva a cabo hasta pasados varios años de convivencia entre los amantes y que se denomina yaukupaku o warmiqorqoy (Millones y Pratt 1989:44). Estas facetas del ritual del matrimonio andino contemporáneo, existieron también en tiempos del Inca.

Guamán Poma proporciona al Rey numerosas soluciones a la corrupción del mundo colonial. La propuesta más extraordinaria, es la que Guamán Poma ofrece para frenar la corrupción de las mujeres andinas: su admisión a las órdenes religiosas. Para Guamán Poma, una de las grandes tragedias, resultado de la colonización, fue la pérdida de la institución de las vírgenes del sol. La cual, como ya mencionamos, constituyó la grandeza y superioridad de los Incas. No es sorprendente, entonces que Guamán Poma sugiera la sustitución de esa institución por la admisión de los indígenas a las ordenes religosas (ver Guamán Poma 1980:813/867[881]).

Cabe mencionar que esta idea -según la perspectiva colonizadora en 1614 fue muy audaz, ya que la represión en contra de la religión andina, durante esta época fue extremadamente severa. Sin embargo, para Guamán Poma esta idea resultó ser la más lógica, a la vez que lo vio como un último recurso para combatir la degeneración de la iglesia andina. Para Guamán Poma, la desintegración moral de la sociedad india laica bajo la influencia extranjera, conjuntamente con los excesos cometidos por los extirpadores de idolatrías, impidieron una 


\section{Alejandra Osorio}

renovación -o una invención verdadera- de la iglesia andina católica (Adomo 1989:75).

Otra de las propuestas al Rey contempla los cambios que Guamán Poma estima debe sufrir la educación de las jóvenes andinas, para solucionar el problema de la promiscuidad sexual:

Que las dichas niñas, mugeres desde adelante se crien con mucho cuydado, castigándolas y dotrinándola con linpiesa. Le enseñe a leer, escriuir $y$ curiucidad $y$ cristiandad $y$ humildad. $Y$ que no se fie del padre doctrinante para que lo eche a perder. $Y$ tengan caridad y ubidencia y seruicio y uirginidad, honrra y cazadas honrradas. $Y$ se den dote como lo manda Dios y la ley de cristiano y de los primeros yndios Uari Uira Cocha Runa, Uari Runa, Purun Runa, Auca Runa. Tanbién tenía gran honrra y uirginidad en el tienpo de los Yngas ydúlatras. Agora los padres, seserdotes de las dotrinas los a echado a perder en este rreyno (Guamán Poma 1980:721/775[789]).

Y para asegurar la proliferación de los andinos es necesario que:

... se quite de los padres $y$ corregidores todas las mitayas y de la dotrina a las dichas solteras y muchachas, niñas y que se enseñen en sus casas como españoles de Castilla. Pues que la ley de cristiano es una en el mundo $y$ en este rreyno. Sea executado y sentenciado desto (Guamán Poma 1980:824-5/879[893]).

El Fruto del Pecado: los Mestizos

Conzedera cómo son tan peresosos los yndios y las yndias... se hazen muy grandes putas y paren 


\section{SEDUCCION Y CONQUTSTA}

mestisos. Y ancí se despuebla los pueblos y se acauan los yndios y multiplican los mestisos. Cin prouecho pierde su Magestad deste rreyno. Conzedera desto (Guamán Poma 1980:871/929[943]).

La consecuecnia de la mezcla sexual entre españoles y mujeres andinas fueron los mestizos. Para Guamán Poma, tanto el mestizaje como la caída de la reproducción biológica de los andinos, fueron las consecuencias más trágicas de la conquista. La nueva "promiscuidad" interétnica se debió, según Guamán Poma, a la ausencia de la ley y de la justicia imperante en la época en que escribió su Carta -una época que describió como un "mundo al revés".

Guamán Poma señala que las mujeres andinas preferian parir un mestizo que un indio. Aunque Guamán Poma lo ve como un gran problema, puesto que si se acababan los indios, por un lado el rey se quedaba sin tributarios y por otro, la raza andina se terminaba. Sin embargo, desde el punto de vista de las mujeres andinas no es difícil de entender. Los mestizos eran súbditos del rey "libres" en términos relativos. Estuvieron exentos del tributo. Por eso, Guamán Poma alega que todas las castas, y las mujeres sin marido, deben estar sujetas al pago del tributo. Y aunque Guamán Poma alega que esto es necesario para el beneficio de la corona, es claro que también lo sugiere para eliminar una de las razones por las cuales -0 que él así percibe- las mujeres andinas procrean mestizos.

Que el cholo y sanbahigo page el pecho $y$ tributo y a de acudir a todos los seruicios personales en este rreyno. Porque del todo es yndio fino, que no se a de entender de la casta de prencipal de título, que el cholo ya no tiene cosa de español. $Y$ en esto tiene la culpa y pecado su padre, maldición de Dios, hijo en el mundo de mala fama, mestizo y cholo, mulato, zanbahigo. 


\section{Alejandra Osorio}

Para ser bueno criatura de Dios, hijo de Adán $y$ de su muger Eua, criado de Dios, español puro, yndio puro, negro puro (Guamán Poma 1980:498/ 526[540]/

El desprecio que Guamán Poma siente hacia las castas $y$ en especial hacia las mestizas es evidente en este pasaje:

Criollas: Cómo las dichas criollas que se crió con la leche de las yndias son peores que mestizas y mulatas, negras, haraganes, mentirosas, enbusteras, bachilleras, golozas y no dizen la uerdad, enemigo de los pobres yndios y no tiene caridad ni buena obra con los pobres.

$\mathrm{Y}$ las dichas mestizas son mucho más peores para las dichas yndias, sus tías $y$ tíos $y$ de sus madres, ama, que son contra los prógimos, pobres yndios. Destas dichas aprenden todas las dichas yndias de ser uellacas y enubedentas. No temen a Dios ni a la justicia. Como uen todo los dichos uellaquerías, son peores yndias putas en este rreyno y no ay rremedio (Guamán Poma 1980:513/541[555]).

Sin embargo, para Guamán Poma no todas las mujeres están corrompidas y perdidas. Es así que en contraste, las mujeres españolas $y$ cristianas $-y$ por ende de raza pura- son muy superiores a las mestizas $e$ indias:

Castilla: Cómo los dichos españoles y españolas que nacieron en Castilla son de mucha honrra $y$ bien dotrinados. Tienen todo entero fe de cristiano $y$ tienen esperansa y caridad, amor de prógimo $y$ tiene justicia $y$ letra de Dios. ...Y oyen el santo euangelio amorosos, caritaibos, umildes. Más quieren ser pobres que rricos y grandes trauajadores, amigos de todos. 


\section{SEDUCCTON Y CONQUISTA}

$Y$ ancí todas las cosas, aunque sea paxa quemado, uale todo lo de Castilla. No se puede escriuirse de tanta cristianidad, obra de misericordia y limosna y serbicio de Dios $y$ de su Magestad...

... $Y$ aci son las mugeres cristianas. $Y$ todo es trauajar y dar limosna y no dar ocación ni enojo a los pobres yndios, que bien sauen que esta tierra lo dio Dios y su Magestad a los yndios deste rreyno. Y ací es grandesa lo de Castilla, cristiano biejo (Guamán Poma 1980:515/543[557]).

Para Guamán Poma la solución evidente al problema étnico y demográfico, es la segregación racial de los pueblos. Si los indios viven separados de los españoles y otras razas, se podrán reproducir y garantizar su sobrevivencia. Para reforzar su argumento sobre la segregación racial, Guamán Poma hace hincapié en que las ordenanzas del Virrey Francisco de Toledo de las reducciones de indios sean cumplidas al pie de la letra:

Ques muy justo y seruicio de Dios y de su Magestad en este rreyno de que los españoles no se puede poblar junto con los yndios en las ciudades ni en las uillas, aldeas ni uaya [a] morar nengún español ni española ni mestizo ni mulato ni zanbahigo ni cholo. Ci fuere española o mestiza o mulata que fuere casado con yndio en este rreyno, que haga los dichos españoles sus pueblos fuera de los yndios en una jomada, ya que no fuera de una legua. Y ci pariere mestiza, chola, lo lleue a la ciudad por el escándalo de ellas (Guamán Poma 1980:504/533[547]-5).

Como parte de la solución Guamán Poma alega que el Rey debe ejercer su autoridad y castigar (como en el tiempo de los Incas) a los malhechores y pecadores: 
Digo a vuestra Magestad que todos los españoles uiuan como cristianos, procuren de casarse con su calidad ygual señora y dexen a las pobres yndias multiplicar y dexen sus pociciones de tierras y casas; las que se an entrado de fuerza, se lo buelba y pague de lo que a gozado y la pena déstos sean executados. Luego, que el que desuirgare a donzella yndia o que hiziere parir a la yndia cazada o le formicare forzalle, sean desterrados sey[s] años de galeras o a Chile y todo sus bienes sea penado para vuestra cámara y pague a la yndia y gastos de justicia. Y ci no lo executare el dicho jues, lo meresca la misma pena contenida. $Y$ todo ello se cumpla y que ninguna justicia no sean contra (Guamán Poma 1980:902/966[984]).

\section{CONCLUSIÓN}

La relación que se entabló a partir del siglo XVI entre los Andes y Europa fue asimétrica. Las caracteristicas más sobresalientes de este encuentro fueron la crisis demográfica que afectó a los pueblos andinos y los cambios culturales, que se dieron por diversas causas. Una transformación se dio en el ámbito religioso por la imposición de una nueva religión, excluyente y monoteísta (ver Duviols 1977, Marzal 1983, Osorio s.f.a.). La introducción de nuevos productos agrícolas, nuevas técnicas de cultivo, y nuevos animales transformó no sólo los modos de producción sino que la vida misma de los andinos. El régimen colonial estableció nuevas demandas de trabajo y de tributo que pesaron sobre la organización social andina, iniciando procesos de fragmentación y recomposición.

La demarcación colonial de los límites jurídicos estipulaban que los indios y los españoles debian constituir dos repúblicas aútonomas y separadas (Lowry 1989:12-3). Sin embargo, la convivencia entre ambos grupos produjo 


\section{SEDUCCION Y CONQUISTA}

una nueva ralea: los mestizos. Los cuales, aunque hijos de ambos, fueron también despreciados por ambos (Flores Galindo 1987:17). En la mente de muchos -como el caso de Guamán Poma- los mestizos constituyeron el "lastre" de la sociedad colonial.

Guamán Poma propuso la segregación racial como una forma de mitigar los abusos cometidos en contra de los andinos. Para Guamán Poma la separación de las dos "naciones" -la de indios y españoles- permitiría la preservación de la raza andina y de ciertos aspectos de su cultura. En el argumento de Guamán Poma la amenaza más grande a la sobrevivencia de la raza india era la proliferación de los mestizos. Para éste, los mestizos en un primer momento fueron el desgraciado resultado del pecado: ${ }^{13}$ las violaciones sexuales sufridas por las mujeres andinas a manos de los españoles. Sin embargo, posteriormente Guamán Poma acusa a las mujeres andinas de convertirse en cómplices de los españoles y de "preferir" estar amancebadas con un cura o un corregidor, que casarse con un indio común. Para Guamán Poma todo esto constituía un "mundo al revés".

Sin embargo, este "mundo al revés", pudo ser una consecuencia lógica a las rígidas normas morales $y$ sociales descritas por Guamán Poma, que gobernaron las vidas de las mujeres durante el incanato. Contraria a la interpretación de Poma, la relación que entablaron algunas mujeres andinas con los colonizadores resultaron ser beneficiosas para ellas. Según Burkett (1978), algunas mujeres andinas durante la colonia gozaron de más independencia y pudieron adentrarse en la nueva sociedad que se forjo, con más facilidad que muchos hombres andinos. Esto se debió a que estas mujeres andinas tuvieron la posibilidad de contraer matrimonio con españoles, 0 de convertirse en sus concubinas. Otras se convirtieron en sus domésticas

13 Ver nota № 4. 


\section{AleJANDRA Osorio}

(ver Glave 1989), y cuidaron de sus hijos. Todo lo cual hizo posible que ellas aprendieran la lengua y la cultura del colonizador $y$ por lo tanto pudieran integrarse a la nueva sociedad con más rapidez y facilidad que los hombres andinos comunes. De igual manera, las mujeres andinas que formaron alianzas matrimoniales con españoles tuvieron la posibilidad de adquirir poder y riquezas dentro de la nueva sociedad colonial.

Por otra parte se ha argumentado (Silverblatt 1987) que las mujeres andinas, en un acto deliberado de resistencia al mundo colonial, se refugiaron en la puna -el lugar más remoto del mundo colonizador-, en un afán de preservar y rescatar la cultura andina de la destrucción que sembraron los españoles en su afán de transformar el mundo andino a imagen y semejanza del mundo peninsular del que provenian (Todorov 1985:17,127-145). Aunque no descartamos la posibilidad de que esto haya sucedido, nos inclinamos a pensar que en efecto muchas mujeres se beneficiaron de la convivencia con los españoles, especialmente en los centros urbanos o cercanos a ellos (ver Osorio s.f.b.). Es evidente que la situación descrita por Guamán Poma, es más cercana a la propuesta por Burkett. Sin embargo, existe la imperante necesidad de estudios demográfico/sociales que nos permitan discemir cuales fueron los patrones migratorios -en términos de género-, durante la colonia, así como las motivaciones que los impulsaron.

Pero fue por medio de la memoria, y en el caso específico de Guamán Poma, la escritura histórica o la "corónica", 14 que los andinos pudieron conservar $-y$ a veces

14 Como ha mencionado Adorno, al identificar como "corónica" su carta al rey Felipe III, Guamán Poma reconoció que el foro de debate de la época estuvo en las narraciones históricas. Fue alli, adonde se discutieron los problemas prácticos y filosóficos producto del descubrimiento y la colonización del Nuevo Mundo. El conocimiento de Guamán Poma de la historia antigua andina y la de la conquista española fue producto de las tradiciones orales andinas y de las tempranas relaciones 


\section{SEDUCCION Y CONQUISTA}

construir- una identidad que les permitió sobrellevar su condición de dominados, a la vez que les permitió enfrentar el cataclismo que significó la conquista (Flores Galindo 1987: 19). La identidad que reinventaron se basó en una reivindicación utópica de lo incaico. La imagen del Imperio Inca (Tawantinsuyu) que se formó en la conciencia popular andina fue la de una sociedad equitativa, en la que no existió el hambre, ni la injusticia, ni la inmoralidad.

Como ha señalado Burga (1988: 234) la obra de Guamán Poma ejemplifica una tradición literaria en la región andina, caracterizada por "un proceso de transición de la tradición oral a la creación de textos literarios" (ver también Adomo et. al. 1982). En la cual se transmiten las angustias y expectativas de una élite andina en decadencia, $y$ bajo el firme dominio colonial y español.

Podríamos decir que Guamán Poma fue un "cautivo" de una tradición cultural europea y de una tendencia utópica aristocrática andina. Su obra revela un conocimiento cabal de la tragedia que significó la dominación colonial, convirtiéndose en el portavoz de una "creciente inclinación a mirar el pasado como una alternativa para el presente". Guamán Poma, como otros autores de la época -Garcilaso de la Vega entre otros- manifestó en su obra, la necesidad de mirar respetuosamente hacia el Cusco, idealizando "lo Inca" (Burga 1987:234).

En el caso específico de Guamán Poma, esta utopía o idealización de lo incaico y lo preincaico se construyó desde una necesidad católica: la de tener que absolver

y crónicas españolas, publicadas a mediados del siglo XVI. El forjamiento de Guamán Poma de la historia se sitúa en el contexto de lo andino y en el entendimiento de la polémica sobre la conquista y la filosofía lascasiana (ver Adorno 1989:88-95 al respecto). Los capitulos sobre el pasado tienen como propósito sustentar las afirmaciones de Guamán Poma sobre el presente para asegurar la enmienda de agravios en el futuro, $y$ de esta manera ellos no son puramente etnográficos ni históricos (Adorno 1989:87). 


\section{Alejandra Osorio}

pecados para poder hablar con autoridad moral frente a la inmoralidad de la dominación colonial. Esta empresa significó tomar el discurso católico sobre las mujeres, en el cual ellas aparecen como un "otro" débil y dispuesto a pecar. De igual manera el discurso desesperanzado de Guamán Poma sobre la conquista y, particularmente, la condición de los andinos bajo el dominio colonial español se manifiesta claramente en la analogía que Guamán Poma utiliza para representarlo: la ruptura del hymen significa la pérdida irreversible del orden social andino. En Guamán Poma esta ruptura se manifiesta físicamente en la proliferación de los mestizos, con lo que se agudiza la decadencia andina, sin esperanzas de recuperación. 


\section{Bibliografía}

ADORNO, Rolena

1989 Cronista y Príncipe. La obra de don Felipe Guamán Poma de Ayala. Lima: Fondo Cultural Pontificia Universidad Católica del Perú.

ADORNO, Rolena, et. al.

1982 From Oral to Written Expression: Native Andean Chronicles of the Early Colonial Period. Syracuse, N.Y.: Maxwell School.

BURGA, Manuel

1988 Nacimiento de una utopía: muerte y resurrección de los Incas. Lima: Instituto de Apoyo Agrario.

\section{BURKETT, Elinor}

1978

"Indian Women and White Society: The Case of Sixteenth-Century Peru", en Asunción Lavrín, ed. Latin American Women: Historical Perspectives, 101-29. Westport, Connecticut: Greenwood Press. 


\section{Alejandira Osorio}

CAVERO CARRASCO, Ranulfo

1986

Maiz, chicha y religiosidad andina. Ayacucho: UNSCH.

DUVIOLS, Pierre

1977 La destrucción de las religiones andinas. México: Universidad Autónoma de México.

FLORES GALNDO, Alberto

1987 Buscando un Inca. Lima: Instituto de Apoyo Agrario.

GLAVE, Luis Miguel

1989 "Mujer indigena, trabajo doméstico y cambio social en el siglo XVII (1684)", en: Trajinantes, 305-362. Lima: Instituto de Apoyo Agrario.

GUAMAN POMA de Ayala, Felipe

1980 Nueva Corónica y buen gobierno. México: Siglo XXI/IEP.

LOWRY, Lyn

1989 "Religiosidad y control social en la colonia: el caso de los indios urbanos de Lima". Allpanchis XX (32): $11-42$.

MACERA, Pablo

1977 "Sexo y Coloniaje", en Trabajos de Historia. Lima: Instituto Nacional de Cultura, III: 297-352.

MARZAL, Manuel

1983 La transformación religiosa peruana. Lima: Pontificia Universidad Católica del Perú.

MILLONES, Luis y PRATT, Mary

1989 Amor Brujo. Imagen y cultura del amor en los Andes. Lima: IEP. 


\section{SEDUCCION Y CONQUSTA}

MURRA, John V.

1975 Formaciones económicas y políticas del mundo andino. Lima: IEP.

OSORIO, Alejandra

s.f.a. "Avances de una interpretación histórica crítica sobre la extirpación de idolatrías en el Perú, (Cajatambo, siglo XVII)", ms.

s.f.b. "Hechiceras y curanderas en la Lima del siglo XVII: Formas femeninas de control y acción social", ms.

ROSTWOROWSKI, María

1988 La mujer en la época prehispánica. Lima:

Documento de trabajo no. 17. IEP.

SANCHEZ-ALBORNOZ, Nicolás

1973 La Población de América Latina. Madrid.

SILVERBLATT, Irene

1987 Moon, Sun and Witches: Gender Ideologies and Class in Inca and Colonial Peru. Princeton: Princeton University Press.

TAYLOR, Gerald

1987 Ritos y tradiciones de Huarochiri del Siglo XVII. Lima: IEP.

TODOROV, Tzvetan

1985 The Conquest of America: The question of the other. New York: Harper \& Row. 